\title{
IDENTIFIKASI SEBARAN SEDIMENTASI DAN PERUBAHAN GARIS PANTAI DI PESISIR MUARA PERANCAK-BALI MENGGUNAKAN DATA CITRA SATELIT ALOS AVNIR-2 DAN SPOT-4
}

\author{
I Nyoman Fegie, Bangun Muljo Sukojo \\ Program Studi Teknik Geomatika FTSP-ITS, Kampus ITS Sukolilo, Surabaya, 60111 \\ Email : fegiepasek@yahoo.com, bangunms@gmail.com
}

\begin{abstract}
Abstrak
Kabupaten Jembrana merupakan salah satu daerah di Pulau Bali yang terkena dampak sedimentasi dan abrasi. Muara Perancak merupakan salah satu daerah yang terkena dampak ditribusi sedimen dari sungai-sungai kecil menuju ke laut yang bermuara di Perancak. Dimana Total Suspended Solid (TSS) merupakan salah satu dari mekanisme dalam pengangkutan sedimentasi. Selain itu, abrasi juga merupakan masalah yang ada di pesisir daerah tersebut.

Beberapa metode dapat digunakan untuk memantau perubahan persebaran TSS dan perubahan garis pantai yang terjadi di wilayah tersebut, salah satunya menggunakan teknologi penginderaan jauh. Data yang digunakan dalam penelitian ini adalah citra satelit ALOS/AVNIR-2 tahun 2008 dan 2010 serta citra satelit SPOT-4 tahun 2012. Dalam menentukan tingkat persebaran TSS di daerah penelitian, digunakanlah algoritma Hendrawan dan Asai yang didasarkan pada Digital Number (DN).

Berdasarkan hasil penelitian, tahun 2008 luasan TSS mencapai 831,22 ha dengan nilai TSS berkisar 0-243 mg/L, tahun 2010 mencapai 960,21 ha dengan nilai TSS berkisar 0-135 mg/L, dan pada tahun 2012 mencapai 1710,16 ha dengan nilai TSS berkisar 0-192 mg/L. Dari ketiga hasil TSS yang ada, didapatkan nilai TSS yang mendominasi di daerah tersebut adalah 1-10 mg/L. Sedangkan perbuahan garis pantai menunjukkan penambahan luas daratan terjadi dari tahun 2008 ke 2010 sebesar 213,05 ha, dan tahun 2010 hingga 2012 terjadi pengurangan luas daratan sebesar 377,05 ha. Peningkatan sebaran konsentrasi TSS setiap tahunnya berpengaruh terhadap perubahan garis pantai pada daerah yang terkena endapan TSS tersebut.
\end{abstract}

Kata Kunci: Total Suspended Solid (TSS), Abrasi, Perubahan Garis Pantai

\section{PENDAHULUAN}

Pulau Bali dikenal merupakan pulau yang terkenal sebagai tujuan berwisata. Daerah pantai merupakan salah satu tujuan favorit dari para wisatawan baik lokal maupun interlokal. Namun masalah yang dihadapi saat ini adalah terdapat beberapa wilayah pantai di Bali yang rusak karena sedimentasi maupun abrasi. Total Suspended Solid (TSS) merupakan salah satu dari mekanisme dalam pengangkutan sedimentasi (Alaerts, 1984). Salah satu penyebabnya dari peristiwa tersebut adalah adanya perubahan iklim secara global dan tingginya aktifitas manusia di sekitar sungai yang kemudian terbawa ke laut melalui muara sungai. Hasil citra satelit tahun 2009 yang dikeluarkan Balai Wilayah Sungai Bali-Penida Direktorat Jenderal Sumber Daya Air Kementerian Pekerjaan Umum tahun 2010 dan dipergunakan Dinas Pekerjaan Umum Provinsi Bali menunjukkan, panjang pantai di Bali yang mengalami abrasi
181,7 kilometer atau 41,5 persen.Dari 181,7 kilometer pantai yang abrasi, sekitar 81,5 kilometer sudah ditangani. Masih 100,2 kilometer pantai yang mengalami abrasi belum ditangani (http://bwsbali.pdsda.net).

Dengan penggunaan teknik penginderaan jauh dapat digunakan untuk mengamati persebaran Total Suspended Solid (TSS) dan dampak dari abrasi yang terjadi di daerah tersebut[3]. Dalam penelitian ini akan mengkaji perubahan sebaran Total Suspended Solid yang bervariasi terhadap waktu menggunakan teknik penginderan jauh dengan menggunakan data Citra satelit ALOS AVNIR-2 tahun 2008 dan 2010 serta SPOT-4 tahun 2012.

Selain itu dalam penelitian ini juga mengetahui perubahan garis pantai yang terjadi dari tahun 2008 hingga 2012 di wilayah pesisir pantai Muara Perancak. Dari hasil penelitian ini diharapkan 
memberikan suatu informasi mengenai sebaran TSS secara multitemporal dan perubahan garis pantai yang terjadi di Muara Perancak, sehingga dapat digunakan sebagai decision making tools untuk pembangunan infrastruktur di sekitar Muara Perancak.

\section{METODOLOGI PENELITIAN}

\section{Lokasi Penelitian}

Penelitian ini dilakukan di sepanjang pesisir pantai Muara Perancak Kabupaten Jembrana, Bali. Kabupaten Jembrana sendiri terletak pada posisi geografis antara $8^{\circ} 09^{\prime} 30^{\prime \prime}$ - $8^{\circ} 28^{\prime} 02^{\prime \prime}$ LS dan $114^{\circ} 25^{\prime} 53^{\prime \prime}$ - $114^{\circ} 56^{\prime} 38^{\prime \prime}$ BT.

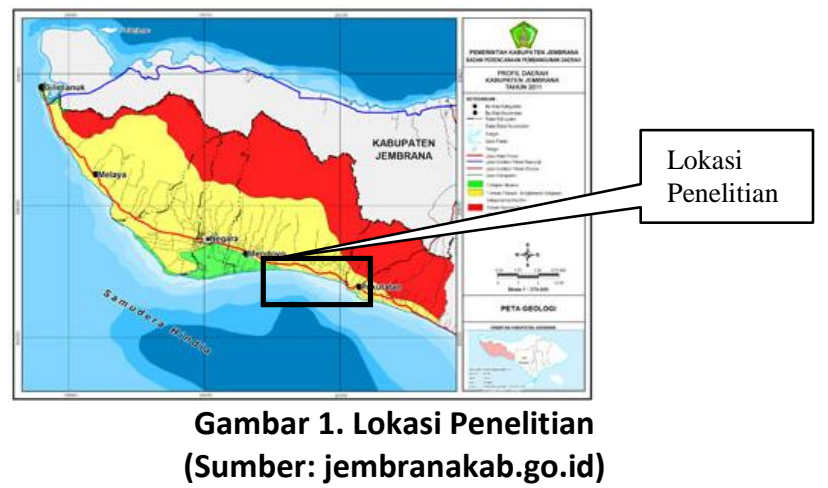

\section{Data dan Perangkat Lunak}

Data yang digunakan dalam penelitian ini adalah :

- Data Spasial

1. Citra ALOS AVNIR-2 tahun 2008 dan 2010 serta SPOT-4 tahun 2012

2. Peta RBI Delodbaleagung skala 1: 25.000 dan Peta Munduk skala 1: 25.000

- Data Non Spasial

1. Data Total Suspended Solid (TSS) yang diperoleh dari pengambilan sampel air di daerah Muara Perancak Bali.

2. Data Pasang Surut Data perairan Selat Bali, sesuai dengan tanggal akuisisi dari satelit.

\section{Tahapan Pengolahan Data}

Pada penelitian ini proses pengolahan data dapat digambarkan seperti diagram alir berikut :

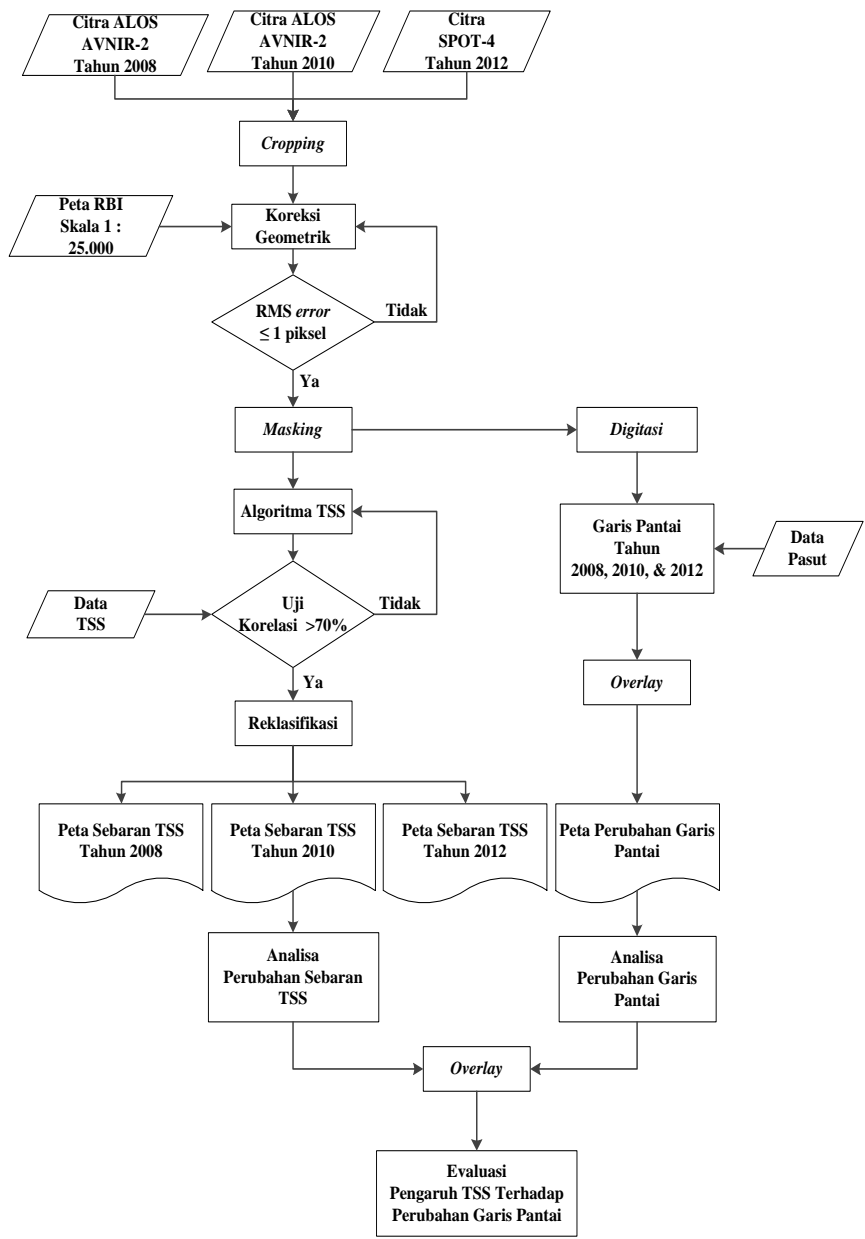

Gambar 2. Diagram Alir Pengolahan Data

Berdasarkan diagram alir diatas, secara umum penelitian ini dibagi menjadi tahapan sebagai berikut :

a. Tahap awal, dimana meliputi proses cropping agar pemrosesan data menjadi lebih efektif, koreksi geometrik pada tiga citra untuk mereduksi kesalahan geometrik yang terjadi pada citra, dan masking untuk memisahkan area daratan dan lautan agar nilai TSS tidak ikut bercampur dengan wilayah daratan saat penerapan algoritma TSS.

b. Tahap pengolahan, dimana dilakukan penerapan algoritma TSS pada area lautan menggunakan algoritma dari Hendrawan dan Assai [4] dengan persamaan sebagai berikut : TSS $(\mathrm{mg} / \mathrm{L})=-1.315 b 1+2.371 b 2-0.791 b 3+$ 9.649

$b 1=$ Digital Number band 1

$b 2=$ Digital Number band 2

b3= Digital Number band 3

Dari hasil penerapan algoritma tersebut akan menghasilkan nilai persebaran TSS dan 
selanjutnya di klasifikasikan. Selain itu pada area daratan dilakukan digitasi untuk menentukan garis pantai pada setiap citra yang kemudian dilakukan overlay dari ketiga garis pantai tersebut untuk mengetahui perubahan garis pantai yang terjadi dari tahun 2008 hingga 2012.

c. Tahap Akhir, dimana nilai TSS hasil penerapan algoritma, selanjutnya dilakukan proses reklasifikasi dengan membuat menjadi 5 kelas untuk TSS dengan mempertimbangkan persebaran terbanyak dari nilai TSS yang ada. Kemudian dilakukan analisa hasil reklasifikasi TSS dengan data insitu. Selain itu analisa juga dilakukan terhadap perubahan garis pantai yang terjadi di kawasan pesisir Muara Perancak serta pengaruh TSS terhadap perubahan garis pantai.

\section{HASIL DAN PEMBAHASAN}

Pada bagian ini akan ditampilkan hasil dari pelaksanaan penelitian yang telah dilakukan mengenai Sebaran TSS dan perubahan garis pantai yang terjadi dari tahun 2008 hingga 2012.

\section{A. Hasil Koreksi Geometrik Citra Dan Sof}

Koreksi geometrik citra satelit ALOS AVNIR-2 dan SPOT-4 dilakukan dengan menggunakan 10 GCP yang terdistribusi secara merata, dari konfigurasi 10 titik GCP, didapatkan nilai RMSe sebagai berikut :

Tabel 1. Nilai RMS Error Masing-Masing Citra

\begin{tabular}{ll}
\hline \hline Titik & RMS \\
\hline 1 & 0,0707 \\
2 & 0,0883 \\
3 & 0,1429 \\
4 & 0,1338 \\
5 & 0,1024 \\
6 & 0,0882 \\
7 & 0,0963 \\
8 & 0,0816 \\
9 & 0,0502 \\
10 & 0.1175
\end{tabular}

(a)

\begin{tabular}{ll}
\hline \hline Titik & RMS \\
\hline 1 & 0,0061 \\
2 & 0,1177 \\
3 & 0,0608 \\
4 & 0,1519 \\
5 & 0,0786 \\
6 & 0,0892 \\
7 & 0,0734 \\
8 & 0,0934 \\
9 & 0,0782 \\
10 & 0.1055
\end{tabular}

(b)

\begin{tabular}{ll}
\hline \hline Titik & RMS \\
\hline 1 & 0,0334 \\
2 & 0,0797 \\
3 & 0,0938 \\
4 & 0,0284 \\
5 & 0,1206 \\
6 & 0,0441 \\
7 & 0,0929 \\
8 & 0,0443 \\
9 & 0,1053 \\
10 & 0.1459
\end{tabular}

(c)
Dimana :

(a) Citra ALOS AVNIR-2 tahun 2008 dengan ratarata RMS error sebesar 0,097 dan SoFnya sebesar 0.6843 . (b) Citra ALOS AVNIR-2 tahun 2010 dengan ratarata RMS error sebesar 0,085 dan SOFnya sebesar 0.5598 .

(c) Citra SPOT-4 tahun 2012 dengan rata-rata RMS error sebesar 0,079 dan SoFnya sebesar 0.4771 .

\section{B. Analisa Hasil Algoritma TSS}

Klasifikasi untuk sebaran TSS di pesisir Muara Perancak menggunakan klasifikasi tak terbimbing (unsupervised) dengan menggunakan hasil penerapan algoritma TSS. Berikut salah satu hasil penerapan algoritma pada citra SPOT-4 tahun 2012.

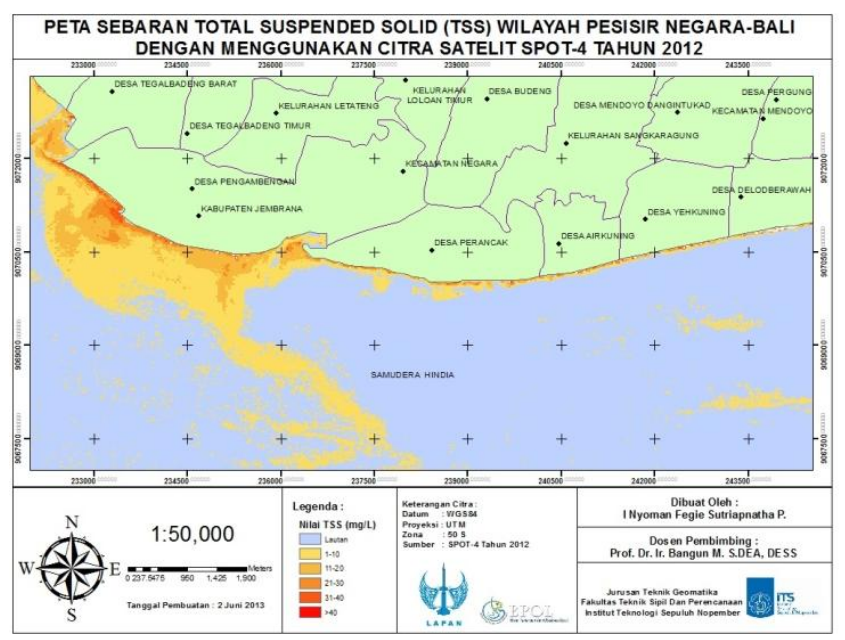

Gambar 3. Peta Sebaran TSS Tahun 2012

Berikut ini tabel perbandingan luasan TSS hasil pengolahan citra.

Tabel 2. Perbandingan Luasan TSS

\begin{tabular}{|c|c|c|c|c|}
\hline \multirow[b]{2}{*}{ No. } & \multirow[b]{2}{*}{$\begin{array}{l}\text { TSS } \\
(\mathrm{mg} / \mathrm{L})\end{array}$} & \multicolumn{3}{|l|}{ Citra \& Tahun } \\
\hline & & $\begin{array}{l}\text { ALOS AVNIR- } \\
2 \\
\text { Tahun } 2008 \\
\text { (ha) }\end{array}$ & $\begin{array}{l}\text { ALOS AVNIR- } \\
2 \\
\text { Tahun } 2010 \\
\text { (ha) }\end{array}$ & $\begin{array}{l}\text { SPOT-4 } \\
\text { Tahun } 2012 \\
\text { (ha) }\end{array}$ \\
\hline 1 & $1-10$ & 607,24 & 719,49 & 1428,76 \\
\hline 2 & $11-20$ & 194,88 & 195,11 & 186,93 \\
\hline 3 & $21-30$ & 11,85 & 15,68 & 55,61 \\
\hline 4 & $31-40$ & 4,81 & 9,10 & 18,15 \\
\hline 5 & $>40$ & 12,44 & 20,83 & 20,71 \\
\hline
\end{tabular}

Dari tabel di atas dapat dilihat bahwa hasil pengolahan citra bervariatif. Berdasarkan hasil pengolahan citra, terdapat penambahan persebaran TSS pada setiap tahunnya. Dimana pada tahun 2008 total jumlah dari seluruh kelas TSS mencapai 831,22 ha, pada tahun 2010 mencapai 960,21 ha, dan pada tahun 2012 mencapai 1710,16 ha. 
Nilai TSS yang menggunakan citra ALOS AVNIR-2 tahun 2008 berkisar antara 1-243 mg/L dan pada tahun 2010 sebesar 1-135 mg/L, sedangkan dengan menggunakan citra SPOT-4 nilai TSS berkisar antara 1-192 mg/L. Perbedaan ini disebabkan beberapa hal, diantaranya jenis citra yang berbeda dengan range panjang gelombang yang berbeda-beda antara citra ALOS AVNIR-2 dan SPOT-4, selain itu waktu pemotretan citra, dan musim. Namun sebaran TSS di pesisir Muara Perancak dari tahun 2008-2012 didominasi oleh nilai TSS sebesar 1-10 mg/l. Dimana Desa Pengambengan dan Desa Tegalbadeng Barat merupakan desa yang terkena dampak persebaran TSS dari Muara Perancak.

Kisaran nilai kekeruhan yang dominan di wilayah pesisisr Muara Perancak berkisar 1-10 mg/L ini sesuai dengan penelitian yang dilakukan Rian (2007), menjelaskan bahwa pada tahun 2006 nilai sebaran TSS di Selat Bali didominasi oleh nilai TSS 0-20 mg/L. Kisaran nilai TSS di Selat Bali sangat bervariatif, hal ini disebabkan posisi Selat Bali yang diapit oleh Samudra Hindia dan Laut Bali. Karena posisi Selat Bali yang terbuka ini, maka arus laut dan gelombang yang terjadi cukup kuat dan terus mengalami pergerakan yang berimbas pada luasan sebaran TSS secara terus menerus. namun terdapat perbedaan hasil antara keduanya. Hal ini disebabkan karena adanya perbedaan algoritma yang digunakan dalam penentuan nilai TSS (Cahyono).

\section{Analisa Nilai TSS Lapangan dan TSS Citra}

Perekaman citra SPOT-4 terjadi pada tanggal 26 April 2012, sedangkan pengambilan sampel dilaksanakan pada tanggal 24 April 2013 di Muara Perancak, meskipun kedua data tersebut memiliki tahun dan tanggal yang berbeda namun masuk dalam bulan yang sama yaitu bulan april. Data lapangan akan dibandingkan dengan data citra yang telah diolah,. Berikut ini adalah tabel perbandingan hasil pengolahan citra SPOT-4 tahun 2012 dengan hasil pengukuran sampel air laut yang dilakukan di laboraturium BPOL-Bali.
Tabel 3. Hasil Uji Lapangan Dengan Pengolahan Citra

\begin{tabular}{|c|c|c|c|c|c|c|}
\hline \multirow[b]{2}{*}{ No. } & \multirow{2}{*}{$\begin{array}{l}\text { Nama } \\
\text { Sampel }\end{array}$} & \multicolumn{2}{|l|}{ Kordinat } & \multirow{2}{*}{$\begin{array}{l}\text { Hasil } \\
\text { Lapangan } \\
(\mathrm{mg} / \mathrm{L})\end{array}$} & \multirow{2}{*}{$\begin{array}{l}\text { Hasil } \\
\text { Citra } \\
(\mathrm{mg} / \mathrm{L})\end{array}$} & \multirow[b]{2}{*}{ Selisih } \\
\hline & & $\begin{array}{l}\text { Easthing } \\
\text { (m) }\end{array}$ & $\begin{array}{l}\text { Northing } \\
\text { (m) }\end{array}$ & & & \\
\hline 1 & S1 & 235828 & 9070366 & 32 & 10 & 22 \\
\hline 2 & S7 & 233184 & 9071173 & 39 & 25 & 14 \\
\hline 3 & S9.20 & 236427 & 9070058 & 22 & 4 & 18 \\
\hline 4 & S14 & 235966 & 9070508 & 29 & 7 & 22 \\
\hline 5 & S15.20 & 236703 & 9070084 & 34 & 14 & 20 \\
\hline 6 & S26 & 236024 & 9070549 & 36 & 15 & 21 \\
\hline 7 & SB1 & 235913 & 9070450 & 21 & 4 & 17 \\
\hline 8 & SB5 & 235758 & 9070151 & 25 & 7 & 18 \\
\hline 9 & SITS & 236194 & 9070550 & 45 & 28 & 17 \\
\hline 10 & SNP05 & 235778 & 9070101 & 15 & 3 & 12 \\
\hline 11 & SNP08 & 236798 & 9070061 & 30 & 8 & 22 \\
\hline 12 & SNP10 & 235411 & 9069827 & 13 & 2 & 11 \\
\hline 13 & SNP11 & 233685 & 9070765 & 36 & 14 & 22 \\
\hline 14 & SNP15 & 238176 & 9069649 & 3 & 1 & 2 \\
\hline 15 & SNP16 & 236312 & 9070028 & 34 & 11 & 23 \\
\hline 16 & SNP18 & 236014 & 9069937 & 24 & 6 & 18 \\
\hline
\end{tabular}

Nilai TSS citra dan TSS lapangan pada setiap titik tidak selalu mendekati. Ada beberapa titik yang memiliki perbedaan yang cukup ekstrim, yaitu di titik nomer 1, 4, 5, 6, 11, 13, dan 15. Grafik perbedaan nilai TSS citra dan TSS lapangan digambarkan pada Gambar 3.3 di bawah ini.

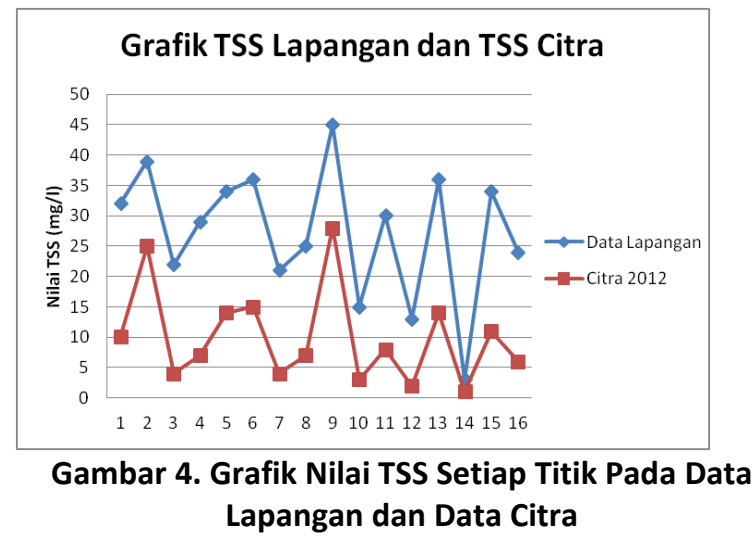

Grafik di atas menunjukan pola distibusi nilai TSS hasil pengolahan citra pada SPOT-4 tahun 2012 dengan hasil pengukuran lapangan. Dari grafik tersebut dapat disimpulkan bahwa antara hasil pengolahan citra dan data lapangan mempunyai kecenderungan pola yang sama. Namun, banyak memiliki perbedaan nilai di hampir semua titik.

Untuk mengetahui kekuatan hubungan antara dua peubah yaitu hasil pengolahan citra dan data pengukuran lapangan, perlu dilakukan perhitungan korelasi. Jika kedua peubah $X$ dan $Y$ berhubungan secara linear, maka koofisien korelasinya menunjukkan derajat hubungan antara peubah tersebut (Furqon, 1999). Berikut ini grafik yang menunjukan korelasi antara data lapangan dan hasil pengolahan citra. 


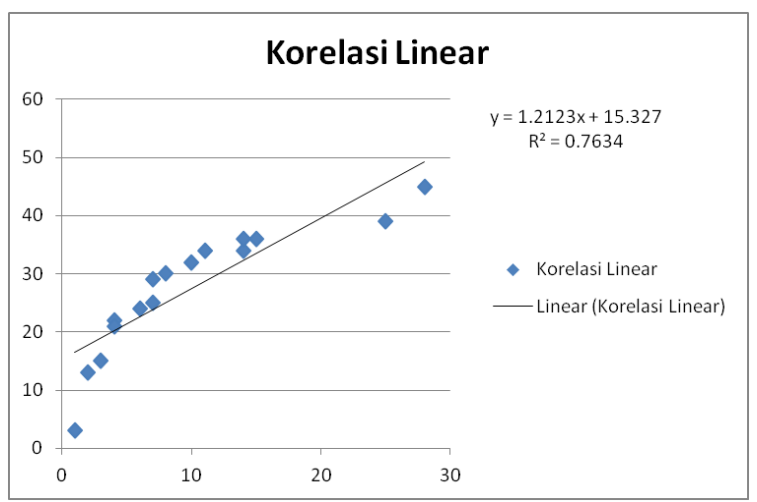

Gambar 5. Grafik Data TSS Lapangan dan Hasil TSS citra SPOT-4 Tahun 2012

Uji korelasi ini dilakukan dengan membandingkan hasil TSS citra dengan hasil data lapangan. Hal ini dilakukan untuk mengetahui sejauh mana korelasi atau kedekatan hasil TSS pengolahan citra dengan hasil lapangan. Besaran koefisien korelasi menunjukkan kuat atau lemahnya hubungan.

Pada uji korelasi ini didapatkan $R^{2}=0,763$, seperti pada gambar 3.4 Dengan persamaan sebagai berikut :

$$
\begin{gathered}
y=1.2123 x+15.327 \\
\text { Dimana : } y=\text { TSS Lapangan }(\mathrm{mg} / \mathrm{l}) \\
x=\text { TSS Citra }(\mathrm{mg} / \mathrm{l})
\end{gathered}
$$

Nilai $\mathrm{R}^{2}=0,763$ bermakna bahwa 0,763 atau $76,3 \%$ diantara keragaman total nilai lapangan (y) dapat dijelaskan oleh hubungan liniernya dengan nilai citra (x). Sehingga dapat disimpulkan antara hasil citra dan data lapangan mempunyai hubungan linier yang kuat. Dari nilai $R^{2}$ ini menjelaskan bahwa prosentase varian dari data citra untuk dapat menggambarkan data di lapangan adalah sebesar $76,3 \%$.

\section{Analisa Sebaran TSS}

Persebaran luasan TSS cenderung mengalami peningkatan luasan dari tahun 2008-2012. Dimana pada tahun 2008 luasan persebaran TSS sebanyak 831,22 ha, tahun 2010 luasan TSS sebanyak 960,21 ha dan meningkat hingga mencapai 1710,16 ha pada tahun 2012. Daerah yang memiliki persebaran TSS yang tinggi pada umumnya berapa pada DAS, muara sungai, dan daerah dekat pantai yang dimana Desa Pengambengan dan Desa Tegalbadeng Barat yang terkena dampak dari persebaran TSS dari Muara Perancak. Selain itu Semakin jauh dari pantai, nilai TSS semakin turun. Daerah yang memiliki nilai TSS tinggi dan berlangsung terus-menerus akan menimbulkan sedimentasi dan terbentuknya daratan yang berakibat pada penambahan luas daratan. Jika dilihat dari tahun 2008-2012, nilai dan luasan sebaran TSS cenderung naik dari tahun ke tahun. Faktor-faktor yang menyebabkan besarnya sedimentasi antara lain sebagai berikut (Asdak, 1995):

1. Sumber sedimen

2. Jumlah sedimen dan jarak antar sumber sedimen

3. System transport

4. Tekstur partikel tanah tererosi

5. Lokasi deposit sedimen

6. Karakteristik DAS

\section{E. Analisa Perubahan Garis Pantai}

Berdasarkan hasil pengolahan yang telah dilakukan terhadap tiga citra, yang dimana didapatkan garis pantai pada setiap tahunnya. Selanjutnya ketiga garis pantai tersebut di overlaykan sehingga mendapatkan bentuk perubahan garis pantainya dan ditampilkan dalam bentuk peta. Namun dalam penelitian ini, hasil perubahan garis pantai yang didapat didasari oleh perbandingan garis pantai dari ketiga citra pada tahun 2008, 2010, dan 2012, yang dimana garis pantai tahun 2008 digunakan sebagai garis pantai acuan untuk mengetahui perubahan yang terjadi pada tahun 2010 dan 2012. Untuk lebih jelasnya terdapat pada gambar di bawah ini.

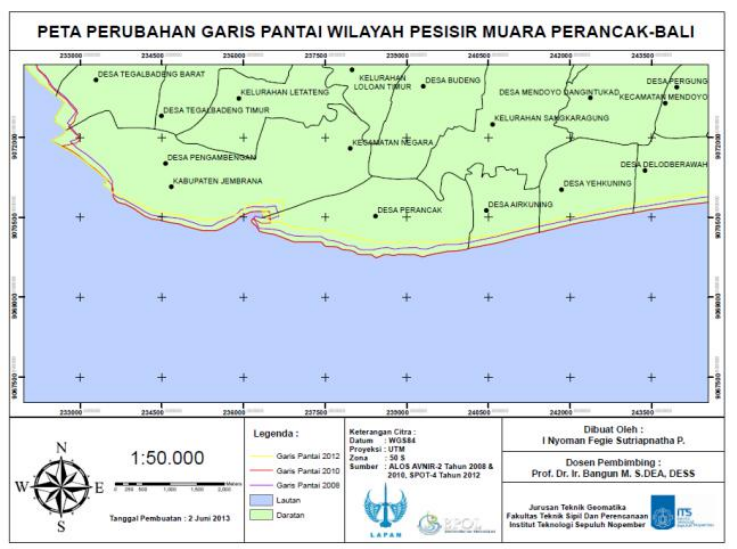

Gambar 5. Peta Perubahan Garis Pantai

Perubahan garis pantai yang terjadi dapat menyebabkan perubahan terhadap luas daratanya. Dari perubahan garis pantai pada daerah penelitian didapatkan adanya perubahan lahan. Untuk lebih jelasnya dapat dilihat pada table di bawah ini. 
Tabel 4. Perubahan Garis Pantai 2008-2012

\begin{tabular}{lll}
\hline \hline Tahun & $\begin{array}{l}\text { Panjang Garis Pantai } \\
(\mathbf{k m})\end{array}$ & Perubahan (km) \\
\hline 2008 & 24,079 & - \\
2010 & 24,337 & $+0,258$ \\
2012 & 24,243 & $-0,094$ \\
\hline
\end{tabular}

Tabel 5. Perubahan Daratan 2008-2012

\begin{tabular}{lll}
\hline \hline Tahun & Luas (ha) & Perubahan (ha) \\
\hline 2008 & 5435,89 & - \\
2010 & 5648,26 & $+212,37$ \\
2012 & 5271,21 & $-377,05$ \\
\hline
\end{tabular}

Berdasarkan table diatas, dapat dilihat terjadi perubahan garis pantai yang diikuti dengan adanya perubahan daratan. Dimana pada tahun 2008 luas daratan sebesar 5435,89 ha, namun pada tahun 2010 mengalami peningkatan menjadi 5648,26 ha dan pada tahun 2012 mengalami penurunan menjadi 5271,21 ha. Dari data tersebut dapat diketahui bahwa dari tahun 2008 sampai 2010 terjadi penambahan luas sebesar 212,37 ha, sedangkan dari tahun 2010 sampai 2012 terjadi penurunan luas sebesar 377,05 ha. Penurunan daratan yang terjadi pada tahun 2010 menuju 2012 dapat terjadi karena adanya perbedaan resolusi antara citra ALOS AVNIR-2 dengan SPOT-4. Dimana resolusi spasial pada citra ALOS AVNIR-2 sebesar $10 \mathrm{~m}$, sedangkan pada citra SPOT-4 sebesar $20 \mathrm{~m}$. sehingga hal ini dapat mengindikasikan penurunan luasan daratan terjadi akibat perbedaan resolusi dari kedua citra.

Perubahan daratan tersebut dapat disebabkan oleh beberapa hal, diantaranya adalah (Tarigan, 2007) :

a. Sedimentasi yang terbawa oleh sungai-sungai yang bermuara di pantai, dalam hal ini Muara Perancak.

b. Reklamasi yang dilakukan oleh penduduk di sekitar pesisir pantai atau para developer.

\section{F. Analisa Berdasarkan Pasang Surut}

Pasang surut mempengaruhi tingkat kekeruhan air laut dan garis pantai. Jika pada kondisi pasang, maka distribusi air akan terjadi dari laut menuju sungai dan daratan. Sehingga pada saat pasang garis pantai akan menurun ke arah daratan sedangkan pada saat surut garis pantai akan meningkat kearah lautan.
Berikut ini garafik pasang surut yang terjadi pada saat pemotretan citra.

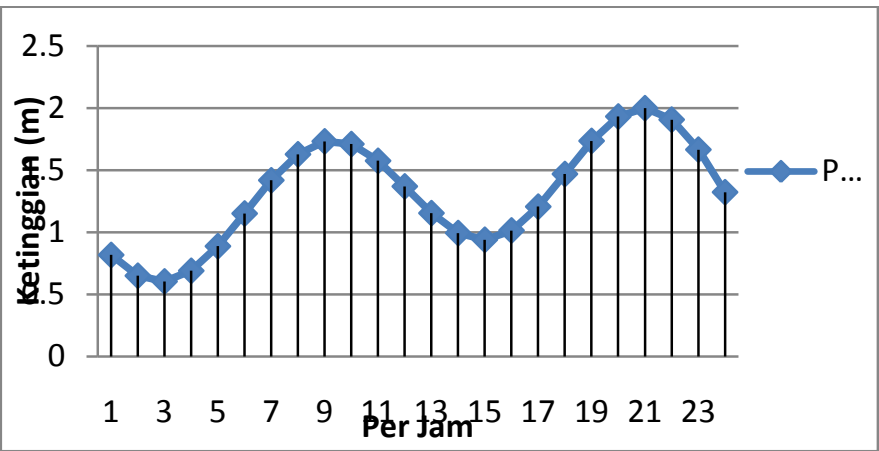

Gambar 6. Grafik Pasang Surut Tanggal 19 maret 2008 (Sumber : DISHIDROS)

Pada waktu pemotretan citra tanggal 19 Maret 2008 kondisi Mean Seal Level (MSL) rata-rata adalah $1,3 \mathrm{~m}$.

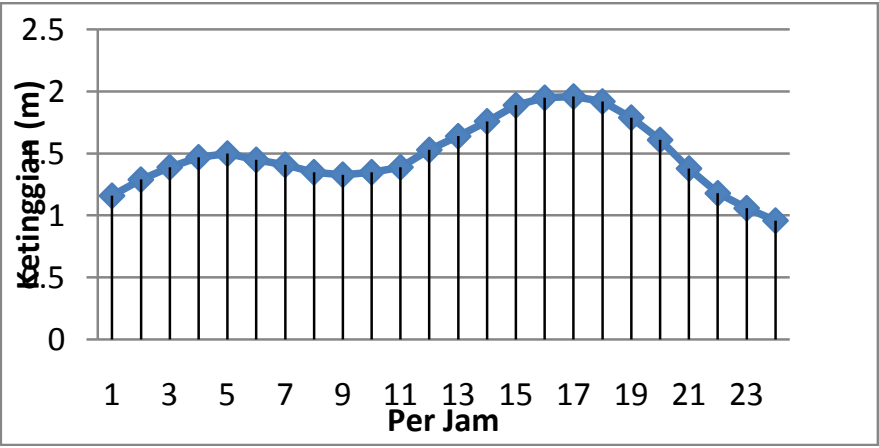

Gambar 3.7 Grafik Pasang Surut Tangga 25 maret 2010

(Sumber : BPOL-Bali)

Pada waktu pemotretan citra tanggal 25 Maret 2010 kondisi Mean Seal Level (MSL) rata-rata adalah $1,5 \mathrm{~m}$.

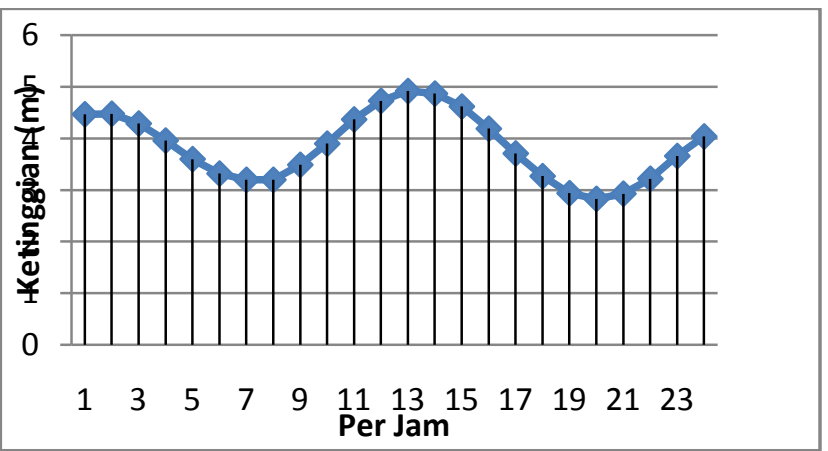

Gambar 3.8 Grafik Pasang Surut Tangga 26 April 2012 (Sumber : BPOL-Bali) 
Pada waktu pemotretan citra tanggal 26 April 2012 kondisi Mean Seal Level (MSL) rata-rata adalah 3,8 m.

Dari ketiga MSL pasang surut tersebut menunjukkan bahwa pasang surut yang terjadi pada saat pemotretan dari ketiga citra tersebut bervariatif, sehingga dapat terjadi perubahan garis pantai di daerah tersebut. Pada tahun 2008 MSL sebesar 1,3 m sedangkan pada tahun 2010 MSL meningkat menjadi $1,5 \mathrm{~m}$, meskipun MSL meningkat namun terjadi pertambahan daratan di tahun 2010. Hal ini terjadi karena adanya beberapa faktor, seperti perbedaan waktu perekaman citra, arus, dan angin. Kemudian pada tahun 2012 terjadi peningkatan MSL yang cukup tinggi sebesar $3,8 \mathrm{~m}$, hal ini menyebabkan terjadi pengurangan daratan di tahun 2012. Peningkatan MSL yang cukup tinggi dapat terjadi karena adanya perbedaan bulan pada saat pemotretan citra, dimana pada tahun 2012 citra SPOT-4 diambil pada bulan April sehingga masuk dalam perubahan musim dari kemarau menuju penghujan. Maka Hal ini dapat membuktikan bahwa pengurangan daratan di daerah tersebut dapat terjadi karena adanya peningkatan MSL di tahun 2012.

Selain itu perubahan garis pantai di daerah tersebut disebabkan adanya proses sedimentasi dan abrasi pantai. Material sedimen yang mengangkut TSS berasal dari sungai dan daerah di sekitar pantai. Hal ini ditandai dengan adanya tanda-tanda erosi yang terjadi pada daerah tersebut. Erosi dapat diidentifikasi karena terjadi perubahan garis pantai yang menuju daratan. Hal ini membuktikan bahwa arus dan gelombang di Selat Bali sangat besar, sehingga menyebabkan abrasi di daerah tersebut dan membawa material tersebut ke sepanjang pantai yang kemudian mengendapkan material tersebut yang menghasilkan sedimentasi pantai.

\section{G. Hubungan TSS Terhadap Perubahan Garis Pantai}

Persebaran luasan TSS dari tahun 2008 hingga 2012 selalu meningkat. Selain meningkatnya persebaran TSS, perubahan juga terjadi pada garis pantai di pesisir Muara Perancak. Dimana garis pantai pada umumnya mengalami perubahan dari waktu ke waktu sejalan dengan perubahan alam seperti adanya aktifitas gelombang, angin, pasang surut, dan arus serta sedimentasi. Dengan meningkatnya persebaran TSS, daerah pesisir Muara Perancak mengalami penambahan daratan. Untuk lebih jelasnya dapat melihat tabel di bawah ini.

Tabel 6. Penambahan Daratan Akibat TSS

\begin{tabular}{ccc}
\hline \hline Tahun & $\begin{array}{l}\text { Luasan Persebaran TSS } \\
\text { (ha) }\end{array}$ & $\begin{array}{l}\text { Penambahan Daratan } \\
\text { (ha) }\end{array}$ \\
\hline 2008 & 831,22 & - \\
2010 & 960,21 & 218,03 \\
2012 & 1710,16 & 39,89 \\
\hline \hline
\end{tabular}

Dari tabel diatas Salah satu faktor dari perubahan bentuk garis pantai yang terjadi di wilayah pesisir disebabkan oleh akresi pantai dimana akresi merupakan kondisi semakin majunya pantai karena penambahan material dari hasil endapatan sungai. Selain itu faktor dari daratan akibat sedimentasi melalui aliran sungai dan adanya tumbuhan pantai. Air sebagai media pembawa sedimen, mengalir melalui aliran sungai menuju muara yang kemudian mengendap. Selain itu hal ini sesuai dengan penelitian yang dilakukan oleh Advend (2006) bahwa perubahan garis pantai di Muara Perancak disebabkan oleh adanya sedimentasi dan abrasi. Material sedimen diperkirakan berasal dari sungai dan daerah di sekitar pantai. Sehingga dapat disimpulkan bahwa peningkatan TSS yang terus meningkat akan dapat berpengaruh terhadap perubahan garis pantai yang terjadi pada daerah yang terkena endapan TSS.

\section{KESIMPULAN DAN SARAN}

Berdasarkan hasil pembahasan dan analisa yang telah dilakukan, diperoleh kesimpulan sebagai berikut :

1. Persebaran nilai TSS untuk setiap tahunnya selalu meningkat, dimana luasan TSS pada tahun 2008 mencapai 831,22 ha dengan nilai TSS berkisar 1-243 mg/L, tahun 2010 mencapai 960,21 ha dengan nilai TSS berkisar 1-135 $\mathrm{mg} / \mathrm{L}$, dan tahun 2012 mencapai 1710,16 ha dengan nilai TSS berkisar 1-192 $\mathrm{mg} / \mathrm{L}$. Pertambahan sebaran TSS ini mengindikasikan bahwa adanya peningkatan aktifitas di sungaisungai yang mengalir menuju Muara Perancak. Untuk sebaran TSS diperlukan penelitian lebih lanjut dengan menggunakan data arus agar 
dapat menentukan pola persebaran TSS di daerah tersebut.

2. Nilai kekeruhan yang dominan untuk area pesisir Muara Perancak pada tahun 2008-2012 sebesar 1-10 mg/l, hal ini berarti perairan Muara Perancak memiliki tingkat kekeruhan yang sangat rendah. Diperlukan penelitian lebih lanjut mengenai sedimentasi menggunakan algoritma yang berbeda.

3. Sejak tahun 2008 hingga 2012 terjadi perubahan garis pantai yang diikuti dengan terjadinya perubahan daratan. Dimana perubahan garis pantai menunjukkan penambahan luasan sebesar 212,37 ha dari tahun 2008 hingga 2010, sedangkan pada tahun 2010 hingga 2012 mengindikasikan bahwa terjadinya pengurangan daratan sebesar 377,05 ha karena peningkatan MSL dan terjadi abrasi di daerah tersebut.

4. Peningkatan TSS yang terus meningkat akan dapat berpengaruh terhadap perubahan garis pantai yang terjadi pada daerah yang terkena endapan TSS. Sehingga dapat dikatakan bahwa TSS merupakan salah satu faktor pendorong terjadinya perubahan garis pantai yang terjadi di pesisir pantai.

\section{DAFTAR PUSTAKA}

Alaerts, G. dan Sri Sumestri, S. 1984. Metoda Penelitian Air. Surabaya: Penerbit Usaha Nasional.
Koescahyono, W. 1997. Pemrosesan Data Citra Satelit Landsat-TM Untuk Interpretasi Dan Mendeteksi Kekeruhan, Pembuatan Peta Tematik Muatan Padatan Tersuspensi Perairan Selat Madura. Surabaya : Laporan Praktik Kerja Lapangan Universitas Hang Tuah.

Hendrawan, G.I., dan Asai, K. 2008. Study Of Suspended Sediment Distribution Using Numerical Model and Satelite Data In Benoa Bay-Bali. Department Of Civil and Environmental Engineering, Yamaguchi University (2-16-1 Tokiwadai, Ube, Yamaguchi 755-8611. Japan).

Cahyono, Rian. Pemetaan Kekeruhan Air Di Selat Bali Dengan Menggunakan Teknologi Penginderaan Jauh. Tugas Akhir Program Studi Teknik Geomatika ITS.

Furqon. 1999. Statistika Terapan Untuk Penelitian. Bandung: CV Alfabeta.

Asdak, C. 1995. Hidrologi dan Pengelolaan Daerah Aliran Sungai. Yogyakarta: Gajah Mada Press.

Tarigan, M. Salam. 2007. Perubahan Garis Pantai Di Wilayah Pesisir Perairan Cisadane, Provinsi Banten. Makara Sains.

Advend, K. 2006. Identifikasi Daerah Abrasi Dan Sedimentasi Di Pulau Bali Dengan Menggunakan Teknologi Penginderaan Jauh (Studi Kasus: Muara Perancak, Bali). Tugas Akhir Program Studi Teknik Geomatika ITS. 